\title{
Superfícies Quádricas Construídas com o Software GeoGebra e a Técnica de Papietagem
}

\author{
Patricia Rodrigues Fortes ${ }^{1}$ \\ Mariza Camargo ${ }^{2}$ \\ Departamento de Engenharia e Tecnologia Ambiental, UFSM/Campus de Frederico Westphalen \\ Sidnei Renato Silveira ${ }^{3}$ \\ Departamento de Tecnologia da Informação, UFSM/Campus de Frederico Westphalen
}

\begin{abstract}
Resumo. Neste trabalho, é descrita uma atividade didática que engloba conhecimentos de Geometria Analítica, Cálculo Diferencial e Integral, habilidades manuais e tecnologias informáticas para obtenção de modelos físicos que representam superfícies quádricas. Propõese, primeiramente, utilizar recursos computacionais do software GeoGebra para estabelecer várias curvas de nível de uma superfície quádrica, e na sequência estas curvas serão usadas para delimitar a elaboração de moldes concretos para construção de tais superfícies, com emprego da técnica artesanal de papietagem. Em especial, foi ilustrada a construção de um parabolóide elíptico.
\end{abstract}

Palavras-chave. GeoGebra, Superfícies Quádricas, Ensino de Matemática, Curvas de Nível.

\section{Introdução}

Em virtude da crescente necessidade de se avaliar e renovar os recursos de ensino utilizados em sala de aula, propõe-se neste trabalho apresentar um texto que explique como confeccionar materiais de apoio (modelos concretos) que representem superfícies quádricas. Para pôr em prática esta ideia, serão aqui integrados conhecimentos matemáticos, recursos tecnológicos (software GeoGebra), habilidades manuais e a técnica de papietagem [4]. Além disso, quer-se com este texto organizar uma atividade que possa guiar e estimular um trabalho a ser efetuado em equipe, promovendo também a integração entre acadêmicos, uma vez que saber trabalhar em grupo e lidar com imprevistos são habilidades a serem desenvolvidas no âmbito universitário.

As superfícies quádricas são tópicos de estudo nas disciplinas de Geometria Analítica e de Cálculo Diferencial e Integral (várias variáveis) do ensino superior, sendo que são modeladas por polinômios de segundo grau de no máximo três variáveis, cujas seções planares

\footnotetext{
${ }^{1}$ patricia@ufsm.br

${ }^{2}$ mariza@ufsm.br

${ }^{3}$ sidneirenato.silveira@gmail.com
} 
são cônicas. Dentre as superfícies quádricas (não degeneradas) mais conhecidas cita-se os elipsóides, hiperbolóides de uma folha, hiperbolóides de duas folhas, cones elípticos, parabolóides elípticos e parabolóides hiperbólicos [1,2]. Nas Tabelas 1 e 2 estão elencadas as equações e os respectivos esboços gráficos que representam as referidas superfícies quádricas (centradas na origem dos eixos coordenados).

Tabela 1: Hiperbolóides e Elipsóide

\begin{tabular}{ccc}
\hline Hiperbolóide de uma folha & Hiperbolóide de duas folhas & Elipsóide \\
\hline$\frac{x^{2}}{a^{2}}+\frac{y^{2}}{b^{2}}-\frac{z^{2}}{c^{2}}=1$ & $\frac{z^{2}}{c^{2}}-\frac{x^{2}}{a^{2}}-\frac{y^{2}}{b^{2}}=1$ & $\frac{x^{2}}{a^{2}}+\frac{y^{2}}{b^{2}}+\frac{z^{2}}{c^{2}}=1$ \\
& & \\
& & \\
\end{tabular}

Tabela 2: Parabolóides e Cone Elíptico

\begin{tabular}{ccc}
\hline Parabolóide elíptico & Parabolóide hiperbólico & Cone elíptico \\
\hline$z=\frac{x^{2}}{a^{2}}+\frac{y^{2}}{b^{2}}$ & $z=\frac{y^{2}}{b^{2}}-\frac{x^{2}}{a^{2}}$ & $z^{2}=\frac{x^{2}}{a^{2}}+\frac{y^{2}}{b^{2}}$ \\
& & \\
& & \\
& &
\end{tabular}

A papietagem é uma técnica artesanal em que se utiliza papéis recortados (ou picados), cola e moldes para a obtenção de esculturas. Neste artigo esta técnica será empregada especificamente na construção de modelos que representam superfícies quádricas $[3,4]$. A estratégia consiste primeiramente na utilização do software GeoGebra para obtenção das curvas de nível que definirão as dimensões do molde da superfície (a ser construído com camadas de isopor revestidas com massa acrílica). A técnica de papietagem dará então forma a uma escultura (que neste caso será uma superfície quádrica) através do revestimento deste referido molde a partir de papéis recortados, cola branca e massa acrílica.

O material básico para confecção de superfícies quádricas pela técnica de papiategem compreende: folhas de papel ofício, impressora, tesoura, cola de isopor, uma folha de isopor de $\frac{1}{2} \mathrm{~cm}$ de espessura, cortador para isopor, massa acrílica, espátula, lixa de parede $\left(\mathrm{n}^{\mathrm{O}}\right.$ 120), lixa de ferro ( $\left.\mathrm{n}^{\mathrm{O}} 36\right)$, vaselina em pasta, cola branca, água, pedaços de papel embrulho, pincel macio, tinta acrílica e verniz. 
Na próxima seção, serão especificadas todas as etapas que levam à construção de um parabolóide elíptico (superfície quádrica escolhida para exemplificar a aplicação da técnica abordada neste trabalho), desde o esboço das curvas de nível, elaboração do molde até se chegar à construção do modelo concreto da superfície quádrica desejada.

\subsection{Parabolóide Elíptico}

O parabolóide elíptico modelado pela equação (1) é uma superfície que não se estende para baixo do plano $x y$ e é ilimitada superiormente (ver gráfico em Tabela 2). É simétrica em relação aos planos $x z$ e $y z$, assim como também é simétrica em relação ao eixo dos $z$. A origem é chamada de vértice, as seções paralelas ao plano $x y$ são elipses, enquanto que as seções paralelas aos outros planos coordenados são parábolas (razão pela qual é denominado parabolóide elíptico).

$$
z=\frac{x^{2}}{a^{2}}+\frac{y^{2}}{b^{2}} \text { para } a>0 \text { e } b>0 .
$$

Intersectando-se o gráfico do parabolóide elíptico de equação (1) com o plano horizontal $z=k$ obtém-se

$$
\frac{x^{2}}{a^{2}}+\frac{y^{2}}{b^{2}}=k
$$

que configura uma curva de nível (linha de contorno bidimensional, neste caso uma elipse) da superfície quádrica. Uma vez que o molde do parabolóide elíptico a ser construído terá camadas de folhas de isopor de $\frac{1}{2} \mathrm{~cm}$ de espessura, torna-se conveniente admitir $k=\frac{n}{2}$, para $n=1,2,3, \ldots$ (valor final para $n$ vai depender da altura desejada para o parabolóide elíptico), e assim a equação (2) fica reescrita na forma:

$$
\frac{x^{2}}{a^{2}}+\frac{y^{2}}{b^{2}}=\frac{n}{2} \text { para } n=1,2,3, \ldots
$$

e esta constitui a equação implícita que deve ser levada ao software GeoGebra para que sejam impressas as curvas de nível do parabolóide elíptico.

\subsubsection{Etapas de Construção do Parabolóide Elíptico}

$1^{\mathbf{a}}$ Etapa) Definição do valor final para $n$.

Além da escolha para os valores das constantes $a$ e $b$, há que se escolher também o valor final para $n$, que define a metade da altura (em centímetros) que o parabolóide elíptico apresentará. Neste trabalho quer-se construir um parabolóide elíptico que apresente $a=$ $3 \mathrm{~cm}, b=2 \mathrm{~cm}$ com altura aproximada de $8 \mathrm{~cm}$, e para tanto deve-se atribuir $n=$ $1,2,3, \ldots, 16$. Portanto, deverão ser esboçadas 16 diferentes curvas de nível (elipses).

$2^{\mathbf{a}}$ Etapa) Esboço das curvas de nível no software GeoGebra.

Tendo-se já escolhido $a=3 \mathrm{~cm}, b=2 \mathrm{~cm}$ e $n=1,2,3, \ldots, 16$, o próximo passo é esboçar através do software GeoGebra duas a duas das 16 curvas de nível definidas pela equação (3) (o traçado conjunto de duas regiões consecutivas vai servir de referência para a colagem mais precisa das camadas de isopor do molde em construção). Na Figura 1 estão três prints da tela do software GeoGebra com os esboços das curvas de nível da equação (3): 
um com $n=1$, outro com $n=1$ e $n=2$ e outro com $n=2$ e $n=3$, sendo que as demais curvas devem também ser obtidas e impressas (até se chegar a $n=15$ e $n=16$ ). Quando a figura a ser impressa estiver pronta na Janela de Visualização do software GeoGebra basta selecionar: Arquivo/Visualizar Impressão/Escala em Centímetros/Imprimir. Antes de cada impressão há que se clicar na Janela de Visualização, pois em caso contrário a impressão estará associada ao conteúdo da Janela de Álgebra (e serão impressas as equações ao invés dos esboços das curvas de nível).

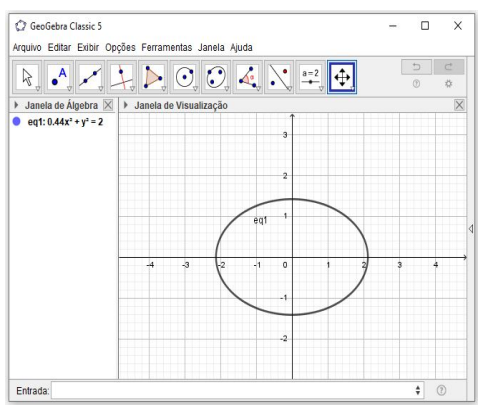

(a) $n=1$

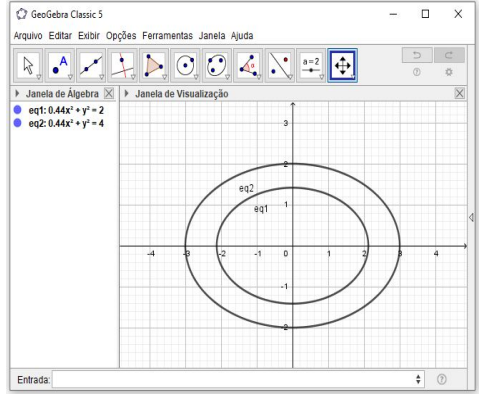

(b) $n=1$ e $n=2$

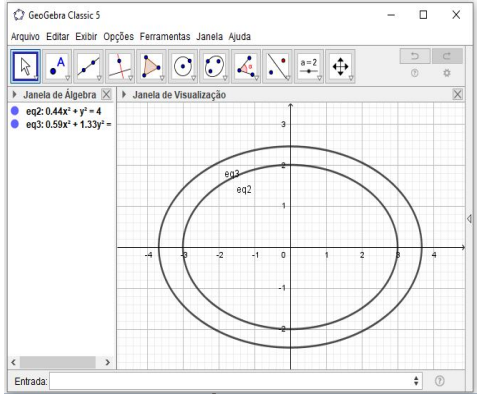

(c) $n=2$ e $n=3$

Figura 1: Curvas de nível no software GeoGebra

$3^{\mathbf{a}}$ Etapa) Molde em camadas de isopor.

Depois que todas as curvas de nível estiverem impressas em papel ofício, deve-se então recortar tais contornos (ver as 16 curvas de nível recortadas na Figura 2(a)) e colá-los na folha de isopor (usar cola de isopor). Após a secagem da cola, deve-se então recortar, com cortador de isopor, as curvas de nível seguindo o contorno indicado no papel impresso. Neste caso específico serão 16 camadas de isopor, que devem ser empilhadas e coladas sequencialmente, da maior para a menor área (ver na Figura 2(b) as camadas de isopor já coladas).

$4^{\text {a }}$ Etapa) Molde com massa acrílica.

Depois que a cola estiver seca entre as camadas de isopor, revestir todo o molde com três camadas de massa acrílica (aguardando o tempo de secagem entre uma camada e outra). Assim que finalizar a aplicação da última camada de massa acrílica, pode-se umedecer as mãos e tentar alisar a superfície do molde (quanto mais lisa estiver a superfície mais fácil será o processo de polimento). Depois que a massa acrílica estiver totalmente seca, promover o polimento do molde, usando primeiramente a lixa de ferro $\left(\mathrm{n}^{\mathrm{O}} 36\right)$ e depois a lixa de madeira ( $\left.\mathrm{n}^{\mathrm{O}} 120\right)$. Após certificar-se de que o molde está completamente liso, revestí-lo com vaselina em pasta, deixando-o pronto para a aplicação da técnica de papietagem. Na Figura 2(c) pode-se observar o molde já revestido de massa acrílica, polido e com vaselina aplicada na superfície.

$\mathbf{5}^{\mathbf{a}}$ Etapa) Técnica da papietagem.

Para iniciar a efetiva construção do parabolóide elíptico através da técnica da papietagem deve-se cobrir o molde com uma primeira camada de papel (recortado ou picado) umedecido somente com água, e na sequência seguir aplicando camadas de pedacinhos de papel umedecidos com cola branca (recomenda-se dissolver a cola com um pouco de 


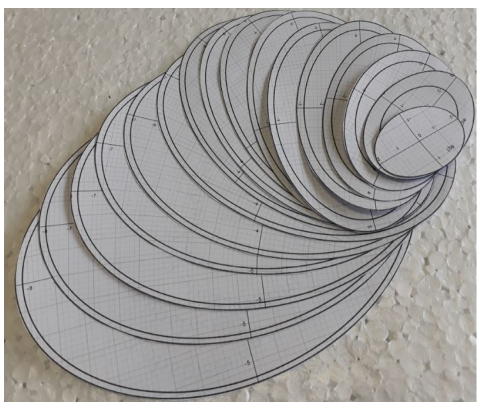

(a) Curvas impressas e recortadas

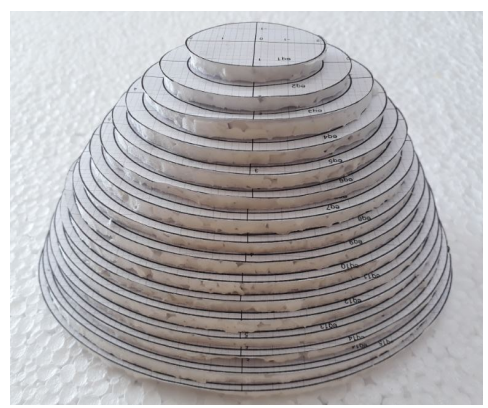

(b) Molde em camadas de isopor

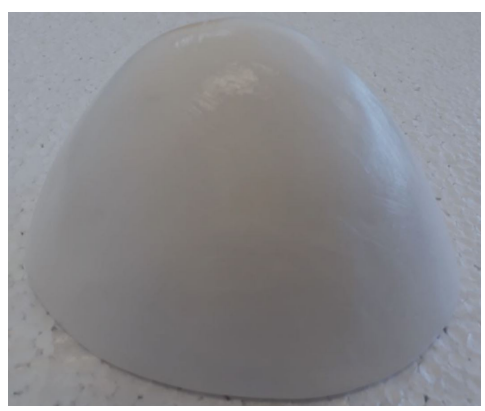

(c) Molde em massa acrílica

Figura 2: Etapas de construção do molde

água, $70 \%$ de cola e 30\% de água). Em média são necessárias sete camadas de papel, e entre uma camada e outra de papel aplicar cola branca utilizando um pincel. Tomar muito cuidado para que não se formem bolhas entre as camadas consecutivas dos pedaços de papel colado. Depois que a cola por sobre a última camada de papel estiver bem seca, retirar a superfície do molde e, com uma tesoura, remover as sobras de papel (na borda da superfície). Na Figura 3, observam-se as imagens do revestimento sequencial do molde através da técnica da papietagem: Figura 3(a) mostra a colagem da primeira camada de papel por sobre o molde, na Figura 3(b) constam as sete camadas de papel (com a cola seca) com a superfície já formada sendo retirada do molde e na Figura 3(c) tem-se a superfície totalmente separada do molde, sendo ainda necessário que sejam cortadas as sobras de papel nas bordas da superfície.

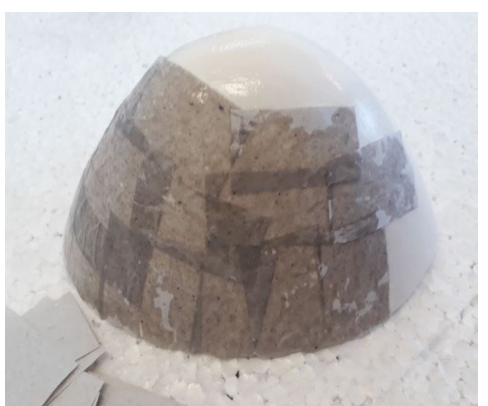

(a) Revestimento do molde

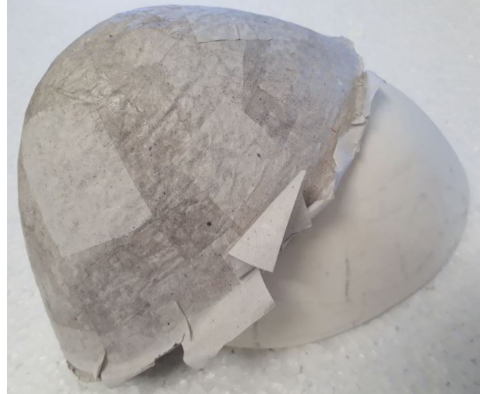

(b) Superfície (sete camadas de papel) sendo retirada do molde

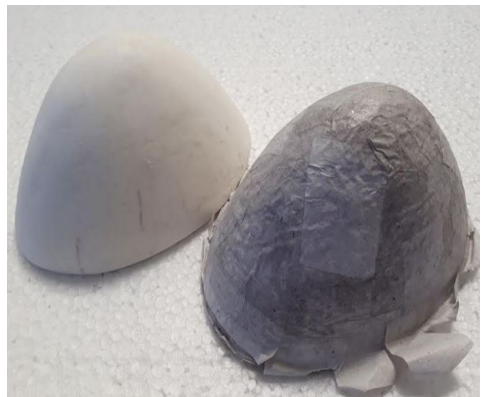

(c) Molde e superfície separados

Figura 3: Etapas de construção da superfície

$6^{\mathbf{a}}$ Etapa) Superfície Quádrica.

Aplicar duas camadas de massa acrílica (aguardando tempo de secagem entre uma aplicação e outra) por dentro e por fora da superfície, tomando cuidado para que toda parte de papel que deu corpo à superfície quádrica fique completamente coberta (na aplicação da segunda camada pode-se umedecer as mãos e tentar alisar a superfície enquanto a massa acrílica estiver fresca). Assim que a massa acrílica estiver bem seca (aproximadamente 
24 horas), lixar toda a superfície quádrica (com os dois tipos de lixa), pintar com tinta acrílica e aplicar verniz. Nas Figuras 4 e 5 imagens das etapas finais de construção do parabolóide elíptico de equação

$$
z=\frac{x^{2}}{3^{2}}+\frac{y^{2}}{2^{2}}
$$

construído de forma a apresentar $8 \mathrm{~cm}$ de altura.

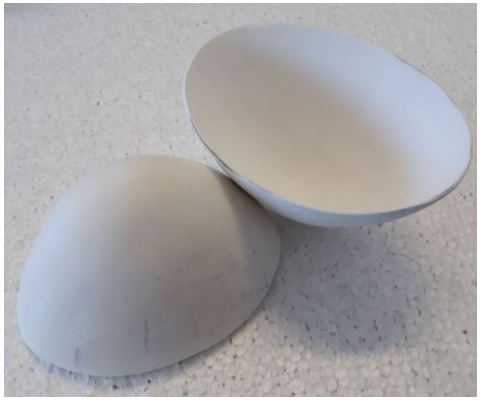

(a) Molde e superfície polida

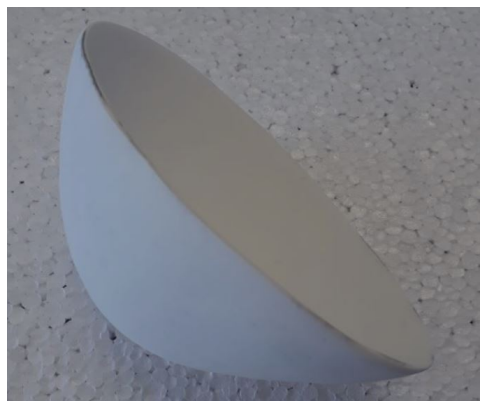

(b) Superfície após polimento

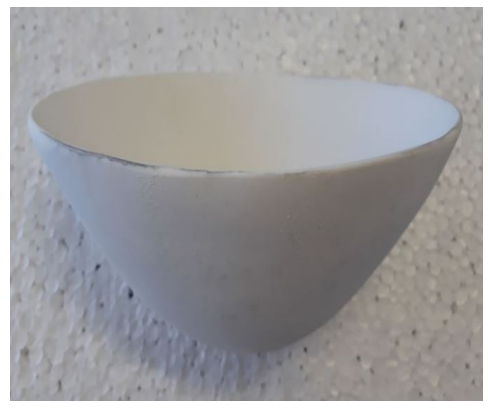

(c) Superfície pronta para pintura

Figura 4: Superfície polida

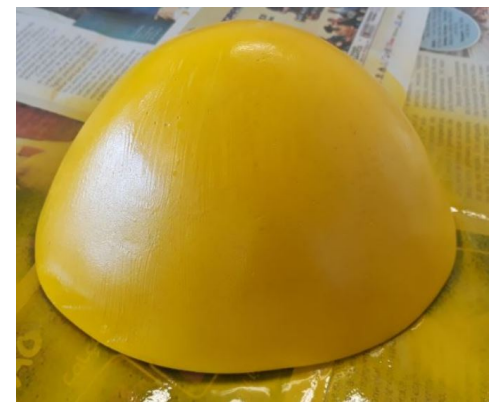

(a) Pintura da superfície

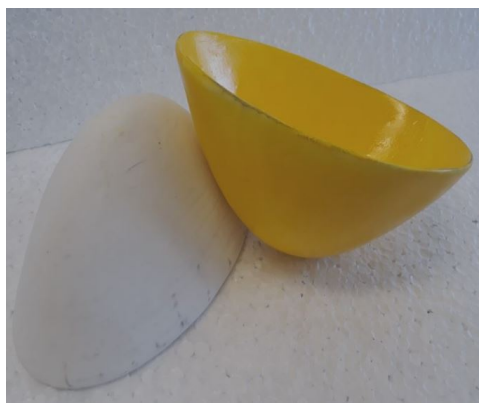

(b) Molde e superfície

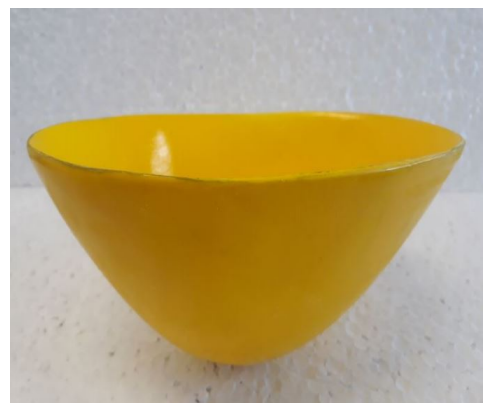

(c) Parabolóide elíptico finalizado

Figura 5: Processo final de construção do parabolóide elíptico

\section{Superfícies Quádricas em Sala de Aula}

Esta proposta será incluida nos planos de aula da disciplina de Cálculo III-A do Curso de Engenharia Ambiental e Sanitária da UFSM/Campus de Frederico Westphalen, sendo que será abordada a partir da proposição de um trabalho em equipe, extraclasse (devido ao tempo necessário para construção do molde e da supefície propriamente dita), em que cada grupo derevá contemplar a construção de uma das superfícies quádricas ilustradas nas Tabelas 1 e 2 (a escolha da superfície se dará por sorteio entre os grupos de trabalho).

A atividade de construção dos modelos concretos das superfícies quádricas será encaminhada no início de cada semestre, uma vez que na referida disciplina as superfícies 
quádricas são abordadas constantemente no estudo das funções de duas ou mais variáveis, curvas de nível, superfícies de nível, derivadas direcionais e gradientes, planos tangentes e vetores normais, máximos e mínimos de funções de duas variáveis e nas integrais duplas e triplas. Assim, é de fundamental importância que os acadêmicos conheçam e saibam distinguir as equações e formas que cada superfície quádrica apresenta, para que então possam compreender as tarefas de investigação que a disciplina vai demandar ao longo de todo semestre. E por esta razão é interessante contar com os modelos concretos das superfícies quádricas para manuseio em sala de aula.

Será solicitado aos grupos de trabalho que façam fotografias e filmagens de todas as etapas consecutivas de construção do modelo concreto da superfície quádrica, para que ao final do processo apresentem em sala de aula o resultado final. Esperamos que esta experiência em equipe contribua para o aprimoramento das habilidades de socialização de conhecimentos, que propicie a troca de experiências e que os acadêmicos sejam incentivados a expor e também ouvir opiniões diferentes.

\section{Conclusões}

Neste texto foram explicadas as etapas de construção de um parabolóide elíptico por intermédio do software GeoGebra e pela Técnica de Papietagem. Para construção de outras superfícies quádricas devem ser seguidas as mesmas seis etapas aqui especificadas, contudo sendo considerada a equação correpondente à nova superfície escolhida (ver equações nas Tabelas 1 e 2), sendo que consequentemente as curvas de nível serão diferentes. Espera-se que este artigo sirva como um incentivo ao uso de materiais manipuláveis no processo de ensino e de aprendizagem, tanto das superfícies quádricas como também dos demais conteúdos em que elas são empregadas, e que a construção destes materiais concretos possibilite a realização de atividades que explorem todo potencial existente nestes objetos, para assim promover a efetiva produção de saberes matemáticos.

\section{Referências}

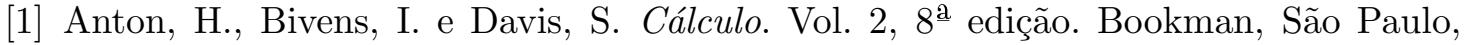
2007.

[2] Leithold, L. O Cálculo com Geometria Analítica. $3^{\text {a }}$ edição. Harbra, São Paulo, 1994.

[3] Vasconcelos, E. e Santana, F. L. J. Oficina: Construção de Superfícies com a Técnica de Papietã. XXVI CNMAC - Congresso Nacional de Matemática Aplicada e Computacional, IBILCE/UNESP, São José do Rio Preto, 2003.

[4] Vasconcelos, E., Andrade, E., Cardoso, M. e Sousa, M. Sólidos \& Superfícies: Construção de Modelos Concretos. EDUFBA - Editora da Universidade Federal da Bahia, Salvador, ISBN: 978-85-232-0795-3, 2011. 